\title{
Hydrogen sulfide attenuates cytokine production through the modulation of chromatin remodeling
}

\author{
ESTER C.S. RIOS ${ }^{1,2}$, BARTOSZ SZCZESNY ${ }^{1}$, FRANCISCO G. SORIANO ${ }^{2}$, GABOR OLAH $^{1}$ and CSABA SZABO ${ }^{1}$ \\ ${ }^{1}$ Department of Anesthesiology, University of Texas Medical Branch, Galveston, TX, USA; \\ ${ }^{2}$ Department of Emergency Medicine, University of São Paulo Medical School, São Paulo, Brazil
}

Received December 11, 2014; Accepted March 19, 2015

DOI: $10.3892 / \mathrm{ijmm} .2015 .2176$

\begin{abstract}
Hydrogen sulfide $\left(\mathrm{H}_{2} \mathrm{~S}\right)$ is an endogenous gaseous biological mediator, which regulates, among others, the oxidative balance of cells under normal physiological conditions, as well as in various diseases. Several previous studies have reported that $\mathrm{H}_{2} \mathrm{~S}$ attenuates inflammatory mediator production. In this study, we investigated the role of $\mathrm{H}_{2} \mathrm{~S}$ in chromatin modulation in an in vitro model of lipopolysaccharide (LPS)-induced inflammation and evaluated its effects on inflammatory cytokine production. Tamm-Horsfall protein 1 (THP-1) differentiated macrophages were pre-treated with sodium hydrosulfide (NaHS) (an $\mathrm{H}_{2} \mathrm{~S}$ donor) at $0.01,0.1,0.5$ or $1 \mathrm{mM}$ for $30 \mathrm{~min}$. To stimulate cytokine production, the cells were challenged with bacterial LPS $(1 \mu \mathrm{g} / \mathrm{ml})$ for $1,4,8$ or $24 \mathrm{~h}$. Histone $\mathrm{H} 3$ acetylation was analyzed by chromatin immunoprecipitation (ChIP), cytokine production was measured by ELISA and histone deacetylase (HDAC) activity was analyzed using a standard biochemical assay. $\mathrm{H}_{2} \mathrm{~S}$ inhibited the production of interleukin-6 (IL-6) and tumor necrosis factor- $\alpha$ (TNF- $\alpha$ ) in a concentration-dependent manner; it was most effective at the two highest concentrations used. This effect was associated with a decrease in histone H3 acetylation at the IL- 6 and TNF- $\alpha$ promoters in the cells exposed to $\mathrm{H}_{2} \mathrm{~S}$ or $\mathrm{H}_{2} \mathrm{~S}+$ LPS The findings of the present study suggest that $\mathrm{H}_{2} \mathrm{~S}$ suppresses histone acetylation, which, in turn, inhibits chromatin open-
\end{abstract}

Correspondence to: Professor Csaba Szabo, Department of Anesthesiology, The University of Texas Medical Branch, 601 Harborside Drive, Building 21, Room 4.202D, Galveston, TX 77555-1102, USA

E-mail: szabocsaba@aol.com

Abbreviations: BCA, bicinchoninic acid; ChIP, chromatin immunoprecipitation; $\mathrm{H}_{2} \mathrm{~S}$, hydrogen sulfide; $\mathrm{H} 3 \mathrm{~K} 9$, lysine 9 of histone $\mathrm{H} 3$; HAT, histone acetyltransferase; H3K27, lysine 27 of histone H3; HDAC, histone deacetylase; HMT, histone methyltransferase; IL-6, interleukin-6; LPS, lipopolysaccharide; NaHS, sodium hydrosulfide; PDF, polyvinylidene fluoride; PMA, phorbol myristate acetate; RIPA buffer, radioimmunoprecipitation assay buffer; SDS, sodium dodecyl sulfate; SEM, standard error of the mean; THP-1, Tamm-Horsfall protein 1 ; TNF- $\alpha$, tumor necrosis factor- $\alpha$

Key words: histone deacetylase, inflammation, hydrogen sulfide, endotoxin ness, leading to a decrease in the gene transcription of various pro-inflammatory cytokines. Therefore, this mechanism may contribute to the previously demonstrated anti-inflammatory effects of $\mathrm{H}_{2} \mathrm{~S}$ and various $\mathrm{H}_{2} \mathrm{~S}$ donors.

\section{Introduction}

Hydrogen sulfide $\left(\mathrm{H}_{2} \mathrm{~S}\right)$ is an endogenous gaseous mediator with regulatory roles in neurotransmission, cardiovascular function and cell metabolism. It also participates in the regulation of the oxidative balance of the cells, under both normal physiological conditions, as well as in various diseases (1-8). Various classes of $\mathrm{H}_{2} \mathrm{~S}$ donors have been tested in multiple models of inflammation. The results have revealed that $\mathrm{H}_{2} \mathrm{~S}$ exerts cytoprotective and anti-inflammatory effects, including the inhibition of multiple pro-inflammatory signaling pathways and a reduction in the production of reactive oxygen and nitrogen species (9-24).

The post-translational modification of histones is one form of epigenetic modifications that alter gene expression (25). Amino acids present in the histone tail can be modified by acetylation, methylation, phosphorylation, ubiquitination and other enzymatic modifications during RNA synthesis (26). Histone acetylation is associated with chromatin unfolding, i.e., it facilitates gene transcription. On the other hand, histone deacetylation inhibits gene transcription. Histone methylation can either inhibit or activate gene transcription, depending on the localization (27). Histone methyltransferases (HMTs, enzymes that transfer acetyl groups to the histone tail at lysine and arginine residues) promote histone methylation, while histone acetylation is mediated by histone acetyltransferases (HATs) that exert their effects at lysines of histones H3 and H4 (26-28). Neither histone methylation nor acetylation is permanent, as the modifications can be removed by histone deacetylases (HDACs) and demethylases, respectively, thus rendering epigenetic regulation a dynamic regulator of gene transcription (29). In the present study, we investigated whether $\mathrm{H}_{2} \mathrm{~S}$ acts as a regulator of chromatin modulation and cytokine production in an in vitro model of inflammation.

\section{Materials and methods}

Cell culture. Tamm-Horsfall protein 1 (THP-1) cells were maintained in RPMI-1640 supplemented with $2 \mathrm{~mm}$ l-glutamine, 
$100 \mathrm{U} / \mathrm{ml}$ penicillin, $100 \mu \mathrm{g} / \mathrm{ml}$ streptomycin and $10 \%$ fetal bovine serum (FBS; Sigma, St. Louis, MO, USA). Ultrapure Escherichia coli 0111:B4 LPS free of lipoproteins was obtained from Invitrogen (San Diego, CA, USA). The cells were plated in $22-\mathrm{mm}$ tissue culture dishes $\left(2 \times 10^{6}\right.$ cells/dish). Macrophage differentiation was induced with phorbol myristate acetate (PMA, $100 \mathrm{nM}$ ) for $5 \mathrm{~h}$. In one set of experiments (pre-treatment experiments) the effects of $\mathrm{H}_{2} \mathrm{~S}$ were examined following a 30-min pre-treatment with sodium hydrosulfide ( $\mathrm{NaHS}$, an $\mathrm{H}_{2} \mathrm{~S}$ donor) (Sigma) at $0.01,0.1,0.5$ or $1 \mathrm{mM}$ followed by a washout, followed by incubation with bacterial lipopolysaccharide (LPS, $1 \mu \mathrm{g} / \mathrm{ml}$ ) in $1 \%$ FSB RPMI-1640 for $1,4,8$ or $24 \mathrm{~h}$. In another set of experiments (co-treatment experiments), NaHS was administered 30 min prior to the LPS administration, without a washout. The control cells were maintained in 1\% FBS RPMI-1640.

Western blot analysis. The cells were placed in RIPA buffer and sonicated (3 times for $10 \mathrm{sec}$ each). The supernatants were preserved and the protein concentration was determined by bicinchoninic acid (BCA) assay. Protein expression was determined by sodium dodecyl sulfate-polyacrylamide gel electrophoresis (SDS-PAGE) under reducing conditions. Cell extracts $(25 \mu \mathrm{g} / \mathrm{ml})$ were boiled in equal volumes of loading buffer (150 mM Tris-HCl, pH 6.8; 4\% SDS; $20 \%$ glycerol; $15 \% \beta$-mercaptoethanol; and $0.01 \%$ bromophenol blue) and were electrophoresed on $8-12 \%$ polyacrylamide gels. Following electrophoretic separation, the proteins were transferred onto PVDF membranes for western blotting. The membranes were blocked with StartingBlock T20 (PBS) Blocking Buffer (Thermo Scientific, Waltham, MA, USA) for $1 \mathrm{~h}$. The following primary antibodies were used: rabbit acetylated histone $\mathrm{H} 3$ at the N-terminal tail (06-599; Millipore, Billerica, MA, USA), trimethyl-histone H3 at lysine (Lys)9 (17-625; Millipore), trimethyl-histone H3 at Lys27 (17-625; Millipore), and HRP-conjugated $\beta$-actin (Santa Cruz Biotechnology, Inc., Santa Cruz, CA, USA). The primary antibodies were incubated overnight at $4^{\circ} \mathrm{C}$ and the membranes were washed twice in TBST. A secondary horseradish peroxidase-conjugated antibody (goat anti-rabbit; Cell Signaling Technology, Danvers, MA, USA) was then applied at a dilution of 1:5,000 for $1 \mathrm{~h}$. Over a 30-min period, the blots were washed twice in TBST, after which they were incubated in enhanced chemiluminescence reagents (SuperSignal Detection kit; Pierce, Rockford, IL, USA). The band intensity of the original blots was quantified using GeneTools (Syngene; Synoptics Ltd., Cambridge, MA, USA) and was normalized to $\beta$-actin expression.

Chromatin immunoprecipitation (ChIP). Chromatin immunoprecipitation was performed using the EZ-ChIP kit following the manufacturer's instructions (17-371; Millipore). Following stimulation, the THP-1 cells were fixed by the addition of $37 \%$ formaldehyde to a final concentration of $1 \%$. After $10 \mathrm{~min}$, 10X glycine was added. The cells were washed with ice-cold phosphate-buffered saline (PBS), collected and centrifuged for $4 \mathrm{~min}$ at $700 \mathrm{x}$ g. The cells were then lysed with SDS lysis buffer. Chromatin was sheared by sonication $(5 \times 10 \mathrm{sec}$ at approximately $30 \%$ of maximum power), centrifuged to pellet debris and in dilution buffer. Chromatin extracts were precleared for $1 \mathrm{~h}$ with a $50 \%$ suspension of protein $\mathrm{G}$ agarose. Immunoprecipitations were carried out overnight at $4^{\circ} \mathrm{C}$ with the following antibodies: ChIPAb trimethyl-histone $\mathrm{H} 3$ at Lys9 (17-625; Millipore), ChIPAb trimethyl-histone $\mathrm{H} 3$ at Lys27 (17-625; Millipore) and acetylated histone H3 at the N-terminal tail (06-599; Millipore). Immune complexes were collected with protein $\mathrm{G}$ for $1 \mathrm{~h}$ and washed 3 times with highsalt buffer (20 mM Tris at pH 8.0,0.1\% SDS, 1\% NP-40, $2 \mathrm{mM}$ EDTA and $0.5 \mathrm{M} \mathrm{NaCl}$ ) followed by washes in low-salt buffer $(50 \mathrm{mM} \mathrm{NaCl})$ and no salt buffer (TE). Immune complexes were extracted in elution buffer and DNA cross-links were reverted by heating at $65^{\circ} \mathrm{C}$ for $12 \mathrm{~h}$. Following proteinase $\mathrm{K}$ digestion, DNA was extracted using spin columns following the manufacturer's instructions. The following promoterspecific primers were used in the polymerase chain reactions (PCRs): TNF- $\alpha$ forward, 5'-GATTCTGAGCAAAATA GCCAGCA-3' and reverse, 5'-GGCTTCCTTCTTGTTG TGTGT-3'; interleukin-6 (IL-6) forward, 5'-CCTAGTTGT GTCTTGCGATG-3' and reverse, 5'-GGAGGGGAGATAG AGCTTCT-3'.

Measurement of cytokine production and HDAC/HAT activity. The medium was collected to determine the levels of tumor necrosis factor- $\alpha$ (TNF- $\alpha$ ) and IL-6 using ELISA kits (R\&D Systems, Minneapolis, MN, USA). HDAC activity was analyzed in the cell extracts by a colorimetric assay (HDAC activity assay kit K331-100; BioVision, Mountain View, CA, USA). As negative control, we added Trichostatin (TSA) to the THP-1 extract at final concentration of $0.01 \mathrm{mM}$ following the manufacturer's instructions. HAT activity was also analyzed in the cell extract using a histone acetyltransferase activity assay (ab65352). All procedures were conducted according to the manufacturer's recommendations.

Statistical analysis. All values are expressed as the means \pm standard error of the mean (SEM) from 5 or 6 repetitions per group for the biochemistry analysis and 3-4 technical replicates for the western blot analyses. Statistical analysis was performed using GraphPad InStat software (GraphPad Software Inc., San Diego, CA, USA). Comparisons among the experimental groups were carried out by analysis of variance and Tukey's post-hoc test. A p-value $<0.05$ was considered to indicate a statistically significant difference.

\section{Results}

$\mathrm{H}_{2} \mathrm{~S}$ attenuates cytokine production and modulates HDAC activity. Pre-treatment with NaHS inhibited the LPS-induced production of IL- 6 and TNF- $\alpha$ in a concentration-dependent manner, as measured by ELISA (Figs. 1 and 2). The effects of NaHS on HDAC activity were analyzed in the THP-1 extracts (Fig. 3A) and in the macrophage cultures (Fig. 3B). HAT activity was analyzed in the macrophage cultures (Fig. 3C). NaHS reduced the activity of HDAC in the cell extracts (Fig. 3A). Moreover, the macrophages pre-treated with NaHS for 30 min exhibited a significant decrease in HDAC activity, as measured at $4 \mathrm{~h}$ (Fig. 3B). In contrast to HDAC activity, HAT activity was not affected by treatment with NaHS (Fig. 3C). $\mathrm{H}_{2} \mathrm{~S}$ modulates histone acetylation and methylation, and regulates histone modifications at the IL- 6 and TNF- $\alpha$ promoters. The effects of NaHS on chromatin were analyzed in the cells pre-treated with NaHS $(0.1,0.5$ and $1 \mathrm{mM}$ for $30 \mathrm{~min}$, followed by stimula- 
A

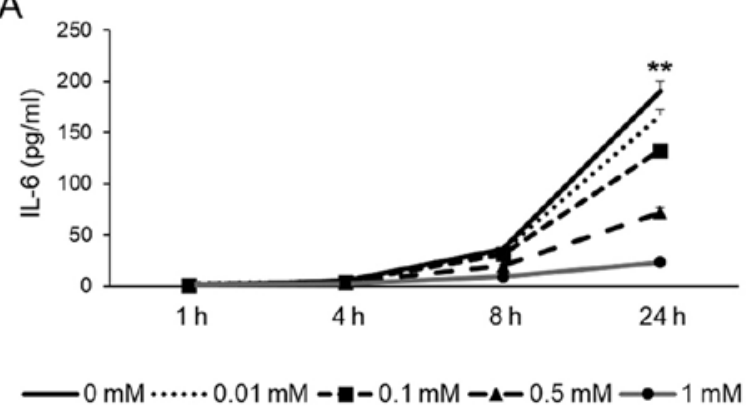

NaHS

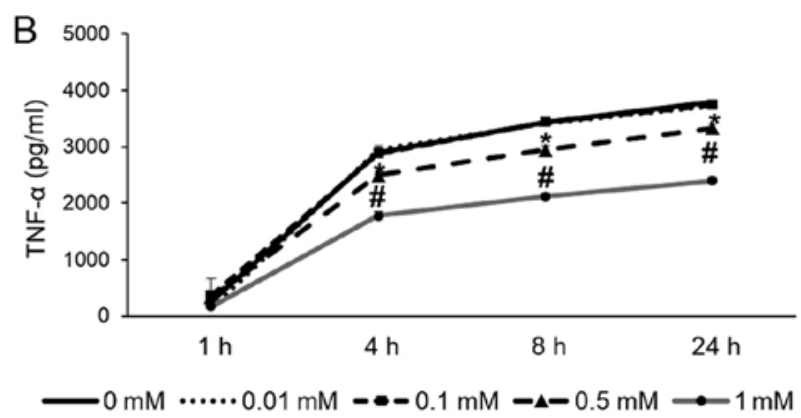

NaHS

Figure 1. Effect of pre-treatment with hydrogen sulfide $\left(\mathrm{H}_{2} \mathrm{~S}\right)$ on lipopolysaccharide (LPS)-induced cytokine production. Differentiated THP-1 macrophages were pre-treated with various concentrations of sodium hydrosulfide (NaHS), for $30 \mathrm{~min}$, followed by a washout, and subsequently challenged with LPS (1 $\mu \mathrm{g} /$ $\mathrm{ml}$ ). The levels of (A) interleukin-6 (IL-6) and (B) tumor necrosis factor- $\alpha$ (TNF- $\alpha$ ) in the supernatant were analyzed at 1, 4, 8 and $24 \mathrm{~h}$ post-LPS challenge. NaHS exerted an inhibitory effect on cytokine production. " $\mathrm{p}<0.05$ vs. $0,0.01$ and $0.1 \mathrm{mM}$; ${ }^{* *} \mathrm{p}<0.05$ vs. all groups; ${ }^{\#} \mathrm{p}<0.05$ vs. all groups.

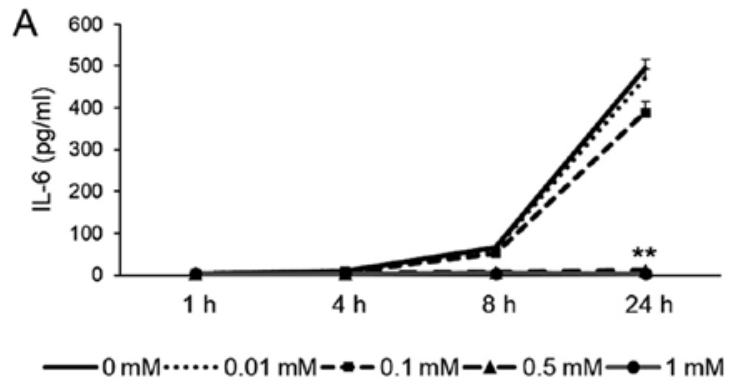

NaHS

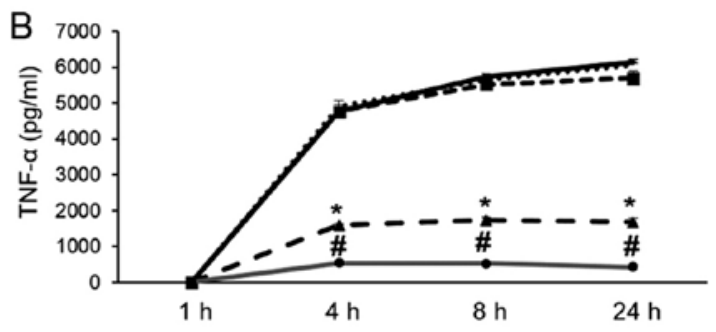

$\longrightarrow 0 \mathrm{mM} \cdots \cdots \cdot 0.01 \mathrm{mM}-\mathbf{m}-0.1 \mathrm{mM}-\Delta-0.5 \mathrm{mM} \longrightarrow-1 \mathrm{mM}$

NaHS

Figure 2. Effect of treatment with hydrogen sulfide $\left(\mathrm{H}_{2} \mathrm{~S}\right)$ on lipopolysaccharide (LPS)-induced cytokine production. Differentiated THP-1 macrophages were treated with various concentrations of sodium hydrosulfide (NaHS) for $30 \mathrm{~min}$, followed by LPS challenge (1 $\mu \mathrm{g} / \mathrm{ml})$. The levels of (A) interleukin-6 (IL-6) and (B) tumor necrosis factor- $\alpha$ (TNF- $\alpha$ ) in the supernatant were analyzed at 1, 4, 8 and $24 \mathrm{~h}$ post-LPS challenge. NaHS exerted an inhibitory effect on cytokine production. ${ }^{*} \mathrm{p}<0.05$ vs. $0,0.01$ and $0.1 \mathrm{mM} ;{ }^{* *} \mathrm{p}<0.05$ vs. all groups; ${ }^{*} \mathrm{p}<0.05$ vs. all groups.
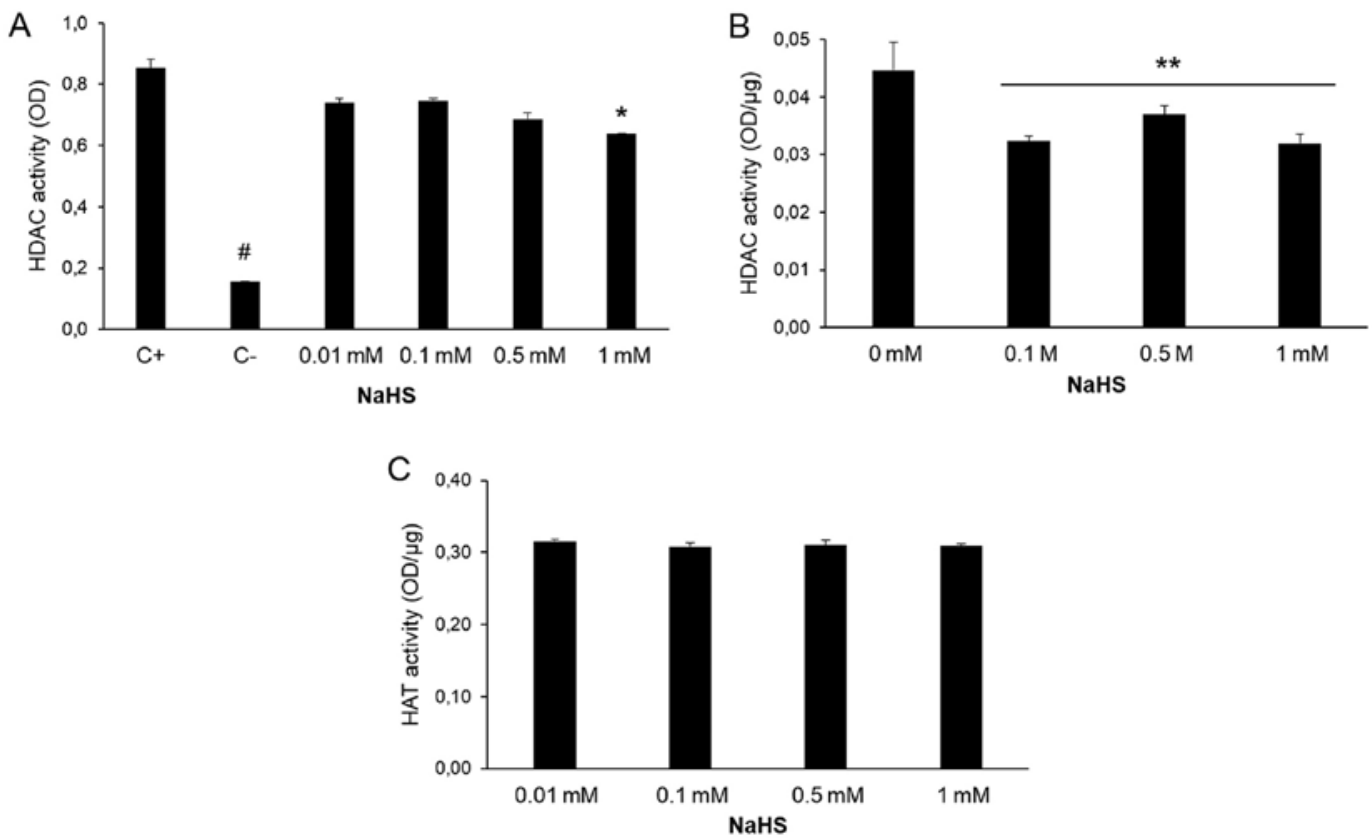

Figure 3. Effect of hydrogen sulfide $\left(\mathrm{H}_{2} \mathrm{~S}\right)$ on histone deacetylase (HDAC) and histone acetyltransferase (HAT) activity. (A) HDAC activity in THP-1 extracts treated with various concentrations of sodium hydrosulfide (NaHS) for $30 \mathrm{~min}$. Trichostatin (TSA; $\mathrm{C}^{-}$) was used as a positive control. (B) HDAC activity was measured in the THP-1 cells pre-treated with NaHS for $30 \mathrm{~min}$, followed by a challenge with lipopolysaccharide (LPS) $(1 \mu \mathrm{g} / \mathrm{ml})$ for $4 \mathrm{~h}$. Note the lack of effect of NaHS alone (A), in contrast to the effect of NaHS pre-treatment (B), when applied prior to LPS challenge. (C) HAT activity was measured in THP-1 cells pretreated with NaHS for $30 \mathrm{~min}$, followed by a challenge with LPS $(1 \mu \mathrm{g} / \mathrm{ml})$ for $4 \mathrm{~h} .{ }^{*} \mathrm{p}<0.05 \mathrm{vs} . \mathrm{C}^{+}, 0.01$ and $0.1 \mathrm{mM} ;{ }^{*} \mathrm{p}<0.05 \mathrm{vs}$. all groups; ${ }^{* *}$ p $<0.05 \mathrm{vs} .0 \mathrm{mM}$. 

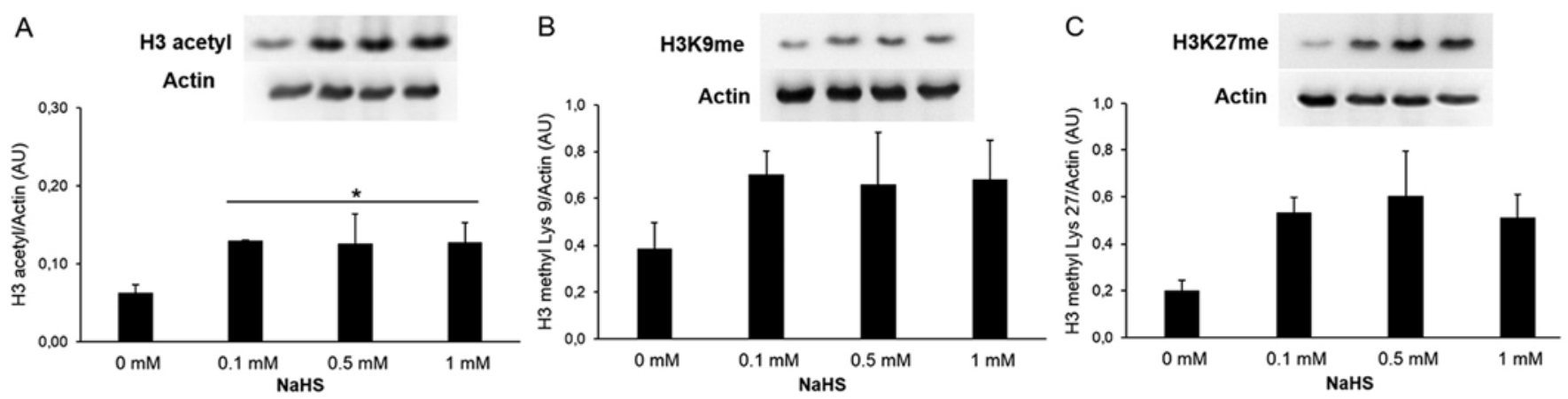

Figure 4. Modification of histone $\mathrm{H} 3$ by hydrogen sulfide $\left(\mathrm{H}_{2} \mathrm{~S}\right)$. The effect of sodium hydrosulfide (NaHS) on histone $\mathrm{H} 3$ (A) acetylation, (B) methylation at lysine (Lys) 9 and (C) methylation at Lys 27 was analyzed in differentiated THP-1 cells followed by treatment with NaHS for 30 min. Cells were harvested at $4 \mathrm{~h}$ after the initiation of NaHS treatment for western blot analysis. Note the positive effect of NaHS on histone H3 modification. "
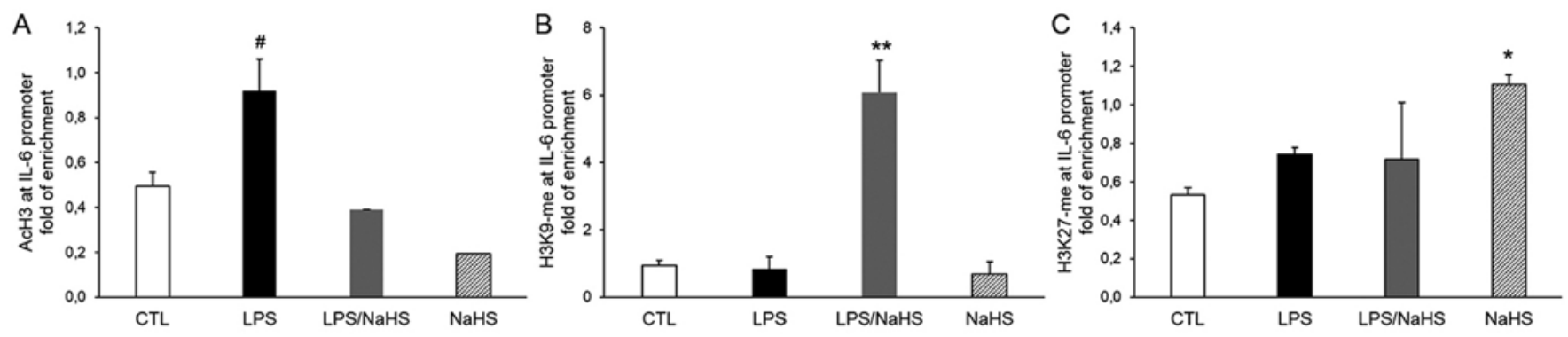

Figure 5. Hydrogen sulfide $\left(\mathrm{H}_{2} \mathrm{~S}\right)$ affects lipopolysaccharide (LPS)-induced histone H3 modification at the promoter of interleukin-6 (IL-6). The (A) acetylation of histone $\mathrm{H} 3$ (AcH3), (B) histone $\mathrm{H} 3$ methylated at lysine (Lys)9 and (C) histone $\mathrm{H} 3$ methylated at Lys27 was analyzed by chromatin immunoprecipitation (ChIP). Note that LPS alone increased the acetylation at the IL-6 gene promoter, which was attenuated by pre-treatment with sodium hydrosulfide (NaHS). In addition, pre-treatment with NaHS increased the methylation of histone H3 at the promoter of IL-6 at Lys9, but not at Lys27. ${ }^{*}<<0.05$ vs. LPS; ${ }^{* *}<<0.05$ vs. control (CTL) and LPS; ${ }^{*} \mathrm{p}<0.05$ vs. all groups.
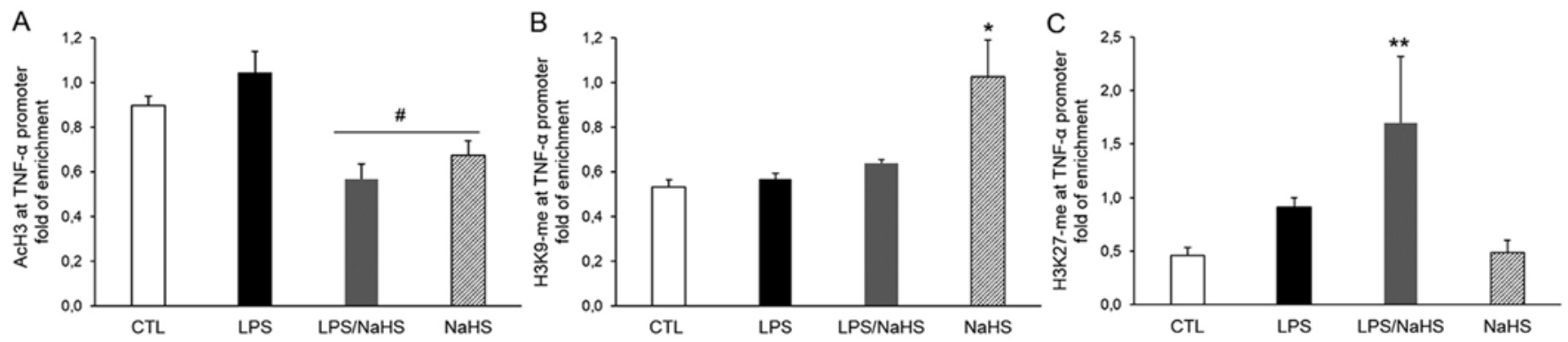

Figure 6. Hydrogen sulfide $\left(\mathrm{H}_{2} \mathrm{~S}\right)$ affects lipopolysaccharide (LPS)-induced histone H3 modification at the promoter of tumor necrosis factor- $\alpha$ (TNF- $\alpha$ ). The (A) acetylation of histone $\mathrm{H} 3$ (AcH3), (B) histone $\mathrm{H} 3$ methylated at lysine (Lys)9 and (C) histone $\mathrm{H} 3$ methylated at Lys27 was analyzed by chromatin immunoprecipitation (ChIP). Pre-treatment with sodium hydrosulfide (NaHS) on its own or together with LPS challenge reduced the acetylation bound to the TNF- $\alpha$ gene promoter. NaHS increased the chromatin methylation at Lys9 but not at Lys27. LPS, on the one hand, increased the association of TNF- $\alpha$ with the methylation of histone $\mathrm{H} 3$ at Lys27 but not at Lys9. NaHS pre-treatment further increased the LPS-induced of methylation histone H3 at Lys27. "p<0.05 vs. LPS; ${ }^{* *} \mathrm{p}<0.05$ vs. all groups; ${ }^{*} \mathrm{p}<0.05$ vs. control (CTL) and NaHS.

tion with LPS $(1 \mu \mathrm{g} / \mathrm{ml})$ for $4 \mathrm{~h}$. Pre-treatment with the $\mathrm{H}_{2} \mathrm{~S}$ donor increased the acetylation of histone $\mathrm{H} 3$ (Fig. 4A) and the methylation at Lys9 (Fig. 4B). The methylation of histone H3 at Lys27 did not present a statically significant change (Fig. 4C). The cells were also analyzed by the chromatin immunoprecipitation method. The chromatin associated with histone H3 (acetylated, methylated at Lys9 or Lys27) was precipitated prior to the determination of TNF- $\alpha$ and IL- 6 gene expression. The values shown represent the enrichment of histone $\mathrm{H} 3$ acetylation or methylation compared to the input. The IL-6 (Fig. 5A) and TNF- $\alpha$ (Fig. 6A) promoters were associated with a lower histone $\mathrm{H} 3$ acetylation in the $\mathrm{H}_{2} \mathrm{~S}$-treated groups. $\mathrm{H}_{2} \mathrm{~S}$ enriched the IL-6 (Fig. 5C) and TNF- $\alpha$ (Fig. 6B) promoters for histone $\mathrm{H} 3$ methylated at Lys27 and Lys9, respectively. On the other hand, the cells that were treated with both NaHS and LPS exhibited an enrichment in histone $\mathrm{H} 3$ methylation at 
Lys9 in the IL-6 promoter (Fig. 5B) and at Lys27 in the TNF- $\alpha$ promoter (Fig. 6C).

\section{Discussion}

The results of the present study demonstrate that $\mathrm{H}_{2} \mathrm{~S}$ modulates the acetylation and methylation of histones. Based on the known role of these epigenetic alterations in the regulation of proinflammatory mediator production (25-29), we hypothesized that these effects may contribute to a reduction in the amount of cytokines released following stimulation with LPS. Moreover, the present findings are also consistent with the conclusion that $\mathrm{H}_{2} \mathrm{~S}$, on its own, induces significant epigenetic alterations.

Given the short half-life of $\mathrm{Na}_{2} \mathrm{~S}$ or $\mathrm{NaHS}$ in aqueous solutions (30), it is interesting to note that even a temporary stimulus (pre-treatment, followed by a washout) with the $\mathrm{H}_{2} \mathrm{~S}$ donor NaHS reduces cytokine production and induces histone modifications. Our results revealed that the $\mathrm{H}_{2} \mathrm{~S}$ donor increased the total methylation and acetylation of histone H3. Since HAT activity was not altered under the same conditions, it can be concluded that the effect of $\mathrm{H}_{2} \mathrm{~S}$ on histone acetylation is due to the direct action of $\mathrm{H}_{2} \mathrm{~S}$ on the reduction of HDAC activity, as demonstrated in cell culture and by a direct biochemical assay. It can also be concluded that, in turn, $\mathrm{H}_{2} \mathrm{~S}$ reduces the chromatin openness by decreasing histone acetylation at the IL- 6 and TNF- $\alpha$ promoters. On the other hand, $\mathrm{H}_{2} \mathrm{~S}$ (either in the absence of any pro-inflammatory stimuli or when applied prior to LPS stimulation) enriches histone $\mathrm{H} 3$ methylation at the TNF- $\alpha$ and IL- 6 promoters.

The importance of chromatin remodeling in the modulation of gene transcription has been investigated in a number of previous studies (25-29). The locus-specific changes in histone $\mathrm{H} 3$ observed in the present study and the associated suppression of inflammatory gene transcription may be one of the mechanisms responsible for the inhibition of cytokine production by $\mathrm{H}_{2} \mathrm{~S}$. Histone acetylation is often related to the chromatin openness, as it weakens the charge attraction between histones and DNA, leading to the decondensation of chromatin, thereby facilitating gene transcription. Both cytokine promoters analyzed in this study exhibited lower acetylation levels at histone $\mathrm{H} 3$ following treatment with NaHS. On the other hand, H3K27 trimethylation brings about transcriptional repression (31), as this epigenetic regulation is related to the silencing of human polycomb target genes (32). Treatment with the $\mathrm{H}_{2} \mathrm{~S}$ donor alone or together with LPS increased H3K27 methylation at both the IL- 6 and TNF- $\alpha$ promoters. A similar response was observed in the methylation of this histone at Lys9, which was enriched at the promoters analyzed in the groups that received NaHS or HaHS together with LPS. H3K9 methylation is linked to heterochromatin and to an endurance of transcriptional repression (33). Furthermore, it has been shown that $\mathrm{H} 3 \mathrm{~K} 9$ methylation acts as a regulatory mechanism for inducible inflammatory genes (33).

It has been demonstrated that, in unstimulated cells, H3K9 methylation is a mechanism for silencing the transcription of some genes whose expression rapidly increases following exposure to stimuli (33). On the other hand, in stimulated cells, H3K9 methylation may also repress inflammatory gene transcription (33). We found that $\mathrm{H} 3 \mathrm{~K} 9 \mathrm{me}$ was associated with IL- 6 but not with TNF- $\alpha$ in stimulated cells. This difference indicates a mechanism which allows for the rapid increase in IL-6 expression, as this cytokine can either function as a pro- or anti-inflammatory cytokin and it is important to the regulation of other inflammatory mediators following LPS stimulation.

In conclusion, the present study established a connection between $\mathrm{H}_{2} \mathrm{~S}$ and epigenetic modulation. Future research on the mechanisms through which this action is associated with the various, previously demonstrated effects (12-16) of $\mathrm{H}_{2} \mathrm{~S}$ on gene transcription, and inflammatory and cell growth signaling is required. In additition, whether endogenous $\mathrm{H}_{2} \mathrm{~S}$, which is similar to exogenous $\mathrm{H}_{2} \mathrm{~S}$ used in the present study, modulates histones remains to be elucidated. Finally, the results of the present study remain to be confirmed under in vivo conditions. While much work remains to be done in this area of research, on the whole, our findings may prove to be beneficial for future studies exploring the the effects of $\mathrm{H}_{2} \mathrm{~S}$ on epigenetic regulation.

\section{Acknowledgements}

This study was supported by a US National Institutes of Health grant (R01GM107846) to C.S.

\section{References}

1. Wang R: The gasotransmitter role of hydrogen sulfide. Antioxid Redox Signal 5: 493-501, 2003.

2. Fiorucci S, Distrutti E, Cirino G and Wallace JL: The emerging roles of hydrogen sulfide in the gastrointestinal tract and liver. Gastroenterology 131: 259-271, 2006.

3. Szabo C: Hydrogen sulphide and its therapeutic potential. Nat Rev Drug Discov 6: 917-935, 2007.

4. Szabo C: Gaseotransmitters: New frontiers for translational science. Sci Transl Med 2: 59ps54, 2010.

5. Whiteman M,Le Trionnaire S, Chopra M, Fox B and Whatmore J: Emerging role of hydrogen sulfide in health and disease: Critical appraisal of biomarkers and pharmacological tools. Clin Sci (Lond) 121: 459-488, 2011.

6. Wang R: Physiological implications of hydrogen sulfide: A whiff exploration that blossomed. Physiol Rev 92: 791-896, 2012.

7. Predmore BL, Lefer DJ and Gojon G: Hydrogen sulfide in biochemistry and medicine. Antioxid Redox Signal 17: 119-140, 2012.

8. Kimura H, Shibuya N and Kimura Y: Hydrogen sulfide is a signaling molecule and a cytoprotectant. Antioxid Redox Signal 17: 45-57, 2012.

9. Esechie A, Kiss L, Olah G, et al: Protective effect of hydrogen sulfide in a murine model of acute lung injury induced by combined burn and smoke inhalation. Clin Sci (Lond) 115: 91-97, 2008.

10. Stuhlmeier KM, Broll J and Iliev B: NF-kappaB independent activation of a series of proinflammatory genes by hydrogen sulfide. Exp Biol Med (Maywood) 234: 1327-1338, 2009.

11. Osipov RM, Robich MP, Feng J, et al: Effect of hydrogen sulfide on myocardial protection in the setting of cardioplegia and cardiopulmonary bypass. Interact Cardiovase Thorac Surg 10: 506-512, 2010.

12. Whiteman M, Li L, Rose P, Tan $\mathrm{CH}$, Parkinson DB and Moore PK: The effect of hydrogen sulfide donors on lipopolysaccharide-induced formation of inflammatory mediators in macrophages. Antioxid Redox Signal 12: 1147-1154, 2010.

13. Zhang J, Sio SW, Moochhala S and Bhatia M: Role of hydrogen sulfide in severe burn injury-induced inflammation in mice. Mol Med 16: 417-424, 2010.

14. Zuidema MY, Peyton KJ, Fay WP, Durante W and Korthuis RJ: Antecedent hydrogen sulfide elicits an anti-inflammatory phenotype in postischemic murine small intestine: Role of heme oxygenase-1. Am J Physiol Heart Circ Physiol 301: H888-H894, 2011.

15. Ang SF, Moochhala SM, MacAry PA and Bhatia M: Hydrogen sulfide and neurogenic inflammation in polymicrobial sepsis: Involvement of substance P and ERK-NF- $\kappa \mathrm{B}$ signaling. PLoS One 6: e24535, 2011. 
16. Gao C, Xu DQ, Gao CJ, et al: An exogenous hydrogen sulphide donor, NaHS, inhibits the nuclear factor $\kappa \mathrm{B}$ inhibitor kinase/nuclear factor $\kappa \mathrm{B}$ inhibitor/nuclear factor- $\kappa \mathrm{B}$ signaling pathway and exerts cardioprotective effects in a rat hemorrhagic shock model. Biol Pharm Bull 35: 1029-1034, 2012.

17. Tokuda K, Kida K, Marutani E, et al: Inhaled hydrogen sulfide prevents endotoxin-induced systemic inflammation and improves survival by altering sulfide metabolism in mice. Antioxid Redox Signal 17: 11-21, 2012.

18. Wang T, Wang L, Zaidi SR, et al: Hydrogen sulfide attenuates particulate matter-induced human lung endothelial barrier disruption via combined reactive oxygen species scavenging and Akt activation. Am J Respir Cell Mol Biol 47: 491-496, 2012

19. Sen N, Paul BD, Gadalla MM, et al: Hydrogen sulfide-linked sulfhydration of NF- $\kappa$ B mediates its antiapoptotic actions. Mol Cell 45: 13-24, 2012.

20. Chan MV and Wallace JL: Hydrogen sulfide-based therapeutics and gastrointestinal diseases: Translating physiology to treatments. Am J Physiol Gastrointest Liver Physiol 305: G467-G473, 2013.

21. Aslami H, Beurskens CJ, de Beer FM, et al: A short course of infusion of a hydrogen sulfide-donor attenuates endotoxemia induced organ injury via stimulation of anti-inflammatory pathways, with no additional protection from prolonged infusion. Cytokine 61: 614-621, 2013.

22. Rivers JR, Badiei A and Bhatia M: Hydrogen sulfide as a therapeutic target for inflammation. Expert Opin Ther Targets 16: 439-449, 2012

23. Benetti LR, Campos D, Gurgueira SA, Vercesi AE, Guedes CE, Santos KL, Wallace JL, Teixeira SA, Florenzano J, Costa SK, Muscará MN and Ferreira HH: Hydrogen sulfide inhibits oxidative stress in lungs from allergic mice in vivo. Eur J Pharmacol 698: 463-469, 2013.
24. Li L, Fox B, Keeble J, et al: The complex effects of the slow-releasing hydrogen sulfide donor GYY4137 in a model of acute joint inflammation and in human cartilage cells. J Cell Mol Med 17: 365-376, 2013.

25. Hitchler MJ and Domann FE: An epigenetic perspective on the free radical theory of development. Free Radic Biol Med 43: 1023-1036, 2007.

26. Fischle W, Wang Y and Allis CD: Histone and chromatin cross-talk. Curr Opin Cell Biol 15: 172-183, 2003.

27. Lachner $M$ and Jenuwein T: The many faces of histone lysine methylation. Curr Opin Cell Biol 14: 286-298, 2002.

28. Noland BJ, Hardin JM and Shepherd GR: Histone acetyltransferase activity in synchronized mammalian cells. Biochim Biophys Acta 246: 263-268, 1971.

29. Fuks F, Hurd PJ, Deplus R and Kouzarides T: The DNA methyltransferases associate with HP1 and the SUV39H1 histone methyltransferase. Nucleic Acids Res 31: 2305-2312, 2003.

30. Papapetropoulos A, Whiteman M and Cirino G: Pharmacological tools for hydrogen sulphide research: a brief, introductory guide for beginners. Br J Pharmacol: June 9, 2014 (Epub ahead of print). doi: 10.1111/bph.12806.

31. Schlesinger Y, Straussman R and Keshet I: Polycomb-mediated methylation on Lys27 of histone $\mathrm{H} 3$ pre-marks genes for de novo methylation in cancer. Nat Genet 39: 232-236, 2007.

32. Kirmizis A, Bartley SM, Kuzmichev A, et al: Silencing of human polycomb target genes is associated with methylation of histone H3 Lys 27. Genes Dev 18: 1592-1605, 2004.

33. Saccani S and Natoli G: Dynamic changes in histone H3 Lys 9 methylation occurring at tightly regulated inducible inflammatory genes. Genes Dev 16: 2219-2224, 2002. 